\title{
КЛИНИКО-ИММУНОГИСТОХИМИЧЕСКАЯ ХАРАКТЕРИСТИКА КОРТИКОСТЕРОМ
}

\author{
'Морозова А.М., ' Цыганкова О.Г., ${ }^{1}$ Юрова Е.В., 'Гараськова Л.К., 'Зотова Ю.Н, ${ }^{2}$ Торохтий Н.А., ${ }^{3}$ Стегний К.В., \\ ${ }^{3}$ Кулакова Т.А., ${ }^{3}$ Гончарук Р.А., ${ }^{3}$ Дмитриев М.О. \\ 'ПКЦД и эндокринных заболеваний ГБУз «ККБ№2», Владивосток. \\ 2Приморский институт региональной патологии. Приморское краевое патологическое бюро, Владивосток. \\ ${ }^{3}$ Центр хирургии медицинского чентра ДВФу, Владивосток.
}

Благодаря активному внедрению высокотехнологичных методов рентген-диагностики в рядовую медицинскую практику, увеличилась частота выявления инциденталом надпочечника(-ов).

ЦЕЛЬ: оценить клинико-иммуногистохимические показатели пациентов, оперированных с синдромом Иценко-Кушинга.

МАТЕРИАЛЫ И МЕТОДЫ: в период с 2015 по 2019 год в Приморском краевом центре диабета и эндокринных заболеваний находились 23 пациента с подтвержденным диагнозом синдром Иценко-Кушинга. Преобладали женщины - 21 человек (91,3\%), мужчин-2 (8,7\%). Пациентов в возрасте от 30 до 49 лет 5 человек (21,7\%); от 50 до 64 лет 11 человек (47,8\%); от 65 до 79 лет 7 человек (30,4\%). Гормонально-активная аденома в правом надпочечнике выявлена у 10 пациентов (43,5\%), слева 13 (46,5\%). Размеры выявленных образований варьировались от - 16×17×22 мм до - 47*50*56мм. Клинически выраженный гиперкортицизм наблюдался у 8 пациентов (34,8\%), субклинический синдром Иценко-Кушинга у 15 (65,2\%). Диагноз подтверждался проведением стандартных исследований: малая дексаметазоновая проба, кортизол слюны в 22:00, кортизол в суточной моче, большая дексаметазоновая проба, адренокортикотропный гормон, а также визуализацией - экспертного уровня компьютерная томография надпочечников с динамическим контрастированием. Всем пациентам была проведена односторонняя адреналэктомия двумя основными способами: ретроперитонеоскопически и лапароскопически. После операции проводилось гистологическое и иммуногистохимическое исследование. Проведен анализ иммуногистохимических исследований. Определялась экспрессия Ki67, Хромогранин А, Синаптофизин, Calretinin, Melan A, Альфаингибин, S100, CK AE1/AE3, р53, АКТГ.

PЕзУльтАТЫ: маркер пролиферации Ki67 реакция (менее 1\%) выявлена в 53,8\% случаев, (3-5\%) в 15,4\%, (до 10\%) в 7,69\%. Р53 (регулятор клеточного цикла) - сильной экспрессии (+++) не было ни в одном образце, что расценивалось как доброкачественный потенциал опухоли. Синаптофизин был положительным с умеренной или сильной интенсивностью окрашивания в 61,53\% опухолевых образцах. Calretinin, Melan-A, Альфа-ингибин - маркеры адренокортикальных клеток с умеренной и высокой интенсивностью преобладали в 46,2\% опухолей. Хромогранин А встречался в 15,3\% опухолевых образцах. S100 маркер нейроэктодермального происхождения (до 10\% клеток) в 30,77\% образцах.; Цитокератины (CK AE1/AE3, Keratinin) с экспрессией в более 30\% клеток опухоли не выявлено ни в одном образце ткани. Значительной разницы в иммуногистохимическом исследовании у пациентов с выраженным гиперкортицизмом и субклиническим синдромом Иценко-Кушинга не обнаружено.

ВЫвОды: результаты иммуногистохимии подтвердили первичное происхождение аденомы из корковых отделов надпочечника, без признаков злокачественности.

КЛЮчЕВЫЕ СЛОВА: аденомы надпочечников; синдром Ииенко-Кушинга; иммуногистохимия; Кі67. 